\title{
Institutionalizing Transformative Learning: The Trees, then the Forest, then the Realization
}

\author{
Ed Cunliff and Jeff King
}

\begin{abstract}
Finding a sense of authentic self as an institution, a true sense of mission, and the means to live that mission were the central focus of a strategic planning process addressed by the University of Central Oklahoma about fifteen years ago. As the institution grew within a metropolitan-serving mission, the goal to transform students from adolescents to adults and find new potential in their lives led to an exciting journey that is still vibrant and relevant today. The theoretical base provided within transformative learning has helped students, staff, and faculty align efforts. This case study provides replicable processes and specifics that may help others find a clearer path for fulfilling their mission. The study describes how the University of Central Oklahoma's (UCO’s) transformative learning focus coalesced and became the point of distinction for a UCO education, helping to ensure that all activity supported our mission-helping students learn. The compelling, lived sense of mission developed from the initial strategic planning process has helped to strengthen the learner-centered culture of the campus while providing a structure that facilitates implementation and assessment.
\end{abstract}

\section{Transformative Learning}

Jack Mezirow's foundational work beginning in the mid-70s is widely considered the origin of transformative learning theory (1981, 1990, 1997, 2000), although its roots can be traced back to humanistic psychology, adult learning theory, and constructivist learning theory. Mezirow commented that: "A defining condition of being human is our urgent need to understand and order the meaning of our experience, to integrate it with what we know to avoid the threat of chaos” (Taylor \& Cranton, 2012, p.73). This phenomenon is a natural part of growing up human. we make meaning of our life experience and create a framework from which to operate and act in the world.

Students of all ages, as well as organizations, connect with the world of higher education within a framework established through experience. They come with an eye toward expanding their worldview; transformative learning is about expanding that view, and as such is a natural process within higher education. Whether it is through the experience of an adolescent on the path to adulthood, an adult ready to enter a new career, or an organization seeking to broaden its perspective by bringing in new views, transformative learning has a growing place in higher education.

Transformation of perspective is a key principle of transformative learning (Dirkx, 2012; Mezirow, 1990). Jack Mezirow's foundational work in transformative learning, and the work of scholars following him, such as Patricia Cranton, emphasize a changed perspective resulting from grappling with events, ideas, and circumstances that challenge a student's status quo

Metropolitan Universities Vol. 29 No. 3 (August 2018), DOI: 10.18060/22407 
thinking. True transformation guides students to discoveries about themselves, to realizations about their relationship to self, others, and the world, and to understandings that transcend the bounds of disciplinary content.

Cranton (2002) distills the theory of transformative learning in this manner:

At its core, transformative learning theory is elegantly simple. Through some event . . . an individual becomes aware of holding a limiting or distorted view. If the individual critically examines this view, opens herself to alternatives, and consequently changes the way she sees things, she has transformed some part of how she makes meaning out of the world. (p. 64)

Morrell and O’Connor (2002) provide a perspective that reflects the depth of change involved in the concept:

... a deep, structural shift in basic premises of thought, feelings, and actions ... a shift of consciousness that dramatically and permanently alters our way of being in the world. Such a shift involves our understanding of ourselves and our self-locations; our relationships with other humans and with the natural world... (p. xvii)

The changes implied within the framework of transformative learning are not superficial, involving the mere memorization of facts; instead, they align more with one of the basic tasks of undergraduate work, which involves transformation from adolescence to adulthood. Benjamin and Crymble (2017) found that youth described the transition as involving three accomplishments: physical responsibility for self, emotional competency, and career attainment (2017, pp. 252). Illeris (2014) succinctly defines transformative learning in a manner that fits well with the transitional perspective of adolescents to adulthood: "The concept of transformative learning comprises all learning which implies changes in the identity of the learner” (2014, p. 40).

\section{Transformative Learning Meets the University of Central Oklahoma}

The changes or accomplishments that students make as they move from adolescence to adulthood are significant transformations, and assisting our students remains part of the many challenges of higher education. It was the recognition of the University's role in this transformative process that encouraged the framing of activities as part of a larger transformative learning process. From this point, the idea of transformative learning began to grow on the campus. UCO's current working definition of transformative learning calls it is a holistic process, which puts students at the center of their own active and reflective learning experiences.

UCO is Oklahoma’s only “metropolitan university” as identified by the Oklahoma State Regents for Higher Education. UCO’s demographics, program mix, student body, faculty, staff, and institutional processes look similar to many mid-size, regional state universities. UCO has about 16,500 students. It is masters-comprehensive in nature; it includes a large and successful teacher education program, serves a high number of commuters, and yet maintains a strong on-campus life for those who choose it. The institution's unique attributes include an international 
population of about 9\%, and a Forensic Science Institute noted as one of a select few nationwide that offers both bachelor's and master's degrees.

UCO operationalizes transformative learning via the Central Six Tenets here described. Its program has replicable elements in terms of helping students learn and creating an over-arching campus climate, which, for UCO, has its basis in transformational learning. The core idea of "helping students learn" as the mission of the university brought together disparate initiatives into a unified framework. This simple mission focus aligns on the mindful, intentional creation of educational experiences, designed to expand graduates' perceptions of the possible, because they have a deeper understanding of themselves, others, and their communities. Elements of the transformative learning mission are present in the tenure and promotion policy for faculty, in internal grant requirements, and in collaborative programs that include faculty, students, and staff. Creating a "real world" higher education experience, blending the campus and the community, is essential to an understanding of transformative learning.

\section{Transformative Birthing: A Case History}

Is it a common occurrence for a major university strategic plan to land on the shelf, collecting dust? If that sounds familiar, then the beginning of the story might have repeated at UCO. What may be different is that under the guidance of Dr. Don Betz, UCO's Provost during the early stages of this process, the academic units continued to push forward the strategic planning effort. Betz, now UCO President, understood the value of a clear focus for moving an institution forward. The academic side of the house persisted in its efforts to formulate and act upon the strategic plan in a manner that would ultimately unite all units under the shared goal of helping students learn through transformative learning experiences. The president's office also invited two other units, Student Affairs and Administration and Information Technology,to attend and participate in Academic Affairs retreats and planning sessions.

In a highly interactive strategic planning session, utilizing concepts from Bennis, Benne, and Chin (1969) that stretched over a two-day period, the Deans and the Provost's staff focused on revising and formulating the institution's mission and values from the academic perspective. The consensus process utilized in the strategic planning resulted in a mission that began simply with helping students learn. While there were those who wanted to leave the mission with the simple and primary focus of helping students learn, the fully crafted mission statement became:

The University of Central Oklahoma (UCO) exists to help students learn by providing education experiences to students so that they may become productive, creative, ethical and engaged citizens and leaders serving our global community. UCO contributes to the intellectual, cultural, economic and social advancement of the communities and individuals it serves. (University of Central Oklahoma, n.d.).

This mission ultimately led to the development of transformative learning at UCO.

On a parallel timeline, though much more organic in its origin, multiple and seemingly disparate programs were brought to campus and gained support from faculty, staff, and students. The American Democracy Project, Undergraduate Research, First-Year Experience, Service 
Learning, and similar programs received a significant amount of attention, offices, and full- or part-time staffing. These programs shared active, experiential learning strategies that could inform both the curricular framework and in co-curricular activities. These and various other programs all intended to help students learn and had essential connections to mission, yet they transcended the curriculum. These programs are often the purview of student affairs and do not lie within the normal scope and practice of academics. George Kuh and his research would ultimately corroborate the value of these programs in his monograph: High-Impact Educational Practices: What They Are, Who Has Access to Them, and Why They Matter (2008).

In addition to the strategic planning effort, a second element that strongly influenced the institution's transformation at this point was a concern shared by most institutions of higher education: how to focus on assessing educational practices. Determining how to measure the various elements of the strategic plan unintentionally spurred the recognition that there were, in fact, significantly connections among these disparate programs. While each program, whether First-Year Experience or Service Learning, needed to be assessed on its own, all programs could be measured together, because all contributed to the overall transformation of undergraduates' perspectives about their individual connections to content, self, others, and the community on local, national, or global levels. This second recognition played a significant part in bringing together the different program perspectives; the implementation team was able to consider the connections rather than the separation, boundaries, or silos between the programs. It was during this process of developing assessment frameworks that the term "transformative learning" first emerged. A theoretical framework did not prompt the term, but rather the practical challenge of evaluating what was done (or said to have been done) educationally. Thinking about assessment clarified a point of connection that neatly paralleled the strategic planning effort. Returning to a holistic, connected framework supported the shared superordinate goal of helping students learn.

The third significant force was the Office of Academic Affairs' desire to collaborate with constituents across the campus. Acting against the natural tendency to protect turf, the Vice President of Academic Affairs reached out to other units and invited them to participate in planning activities. This invitation initially implied "listen and comment," but progressed to a more inclusive process. There was also an intuitive understanding that the university was a single system and its various units operated with the singular goal of helping students learn. The Vice Presidents of Student Affairs, Enrollment Management, Information Technology, and Administration were invited to semi-annual retreats addressing the academic strategic plan, and became regular attendees.

The three aforementioned processes pursued the same mission and commitment to students' learning, more than by any formulated strategic model. John Dirkx (2012), a leading scholar in the area of transformative learning, might consider this within the concept of "soul work," guided by the heart because the commitment stemmed from a deep appreciation for students and all participants involved in the learning process. This point in the UCO transformation is also indicative of systems thinking within an inclusive atmosphere, in this case a moment when the vice presidents from all areas came together to formulate a single model. The vice presidents, working within the President's Cabinet, collectively formalized and created the Central Six Tenets, thus giving all other factors a formal, university-wide direction. It was at this point that the concept of transformative learning was officially included in the mission, reading: 
The University of Central Oklahoma (UCO) exists to help students learn by providing transformative education experiences to students so that they may become productive, creative, ethical and engaged citizens and leaders serving our global community. UCO contributes to the intellectual, cultural, economic and social advancement of the communities and individuals it serves” (University of Central Oklahoma, n.d.).

This revised mission statement and the Central Six Tenets (discipline knowledge; global and cultural competencies; health and wellness; leadership; research, creative and scholarly activity; and service learning and civic engagement, more conveniently termed the "Central Six") became the foundation for UCO's transformative learning.

What does it take personally and professionally to accomplish such goals? Among several factors, the UCO campus model suggests a willingness to share, which often involves giving up tightly managed ownership or giving up turf and silos to support the entire institution and its mission. The concept of synergy is critical because it allows the production of a win-win situation to support student learning. Perhaps most importantly, the commitment to students must be lived and not just discussed. As UCO solidified its commitment to the Central Six principles, it was important to have the sense that specific actions adopted worked in support of the research regarding High Impact Practices.

\begin{tabular}{|ll}
\hline UCO's Central Six Tenets & Kuh's High-Impact Practices \\
\hline Discipline Knowledge & $\begin{array}{l}\text { First-Year Seminars } \\
\text { Common Intellectual } \\
\text { Experiences }\end{array}$ \\
Leadership & $\begin{array}{l}\text { Learning Communities } \\
\text { Internships }\end{array}$ \\
$\begin{array}{r}\text { Research, Creative, \& } \\
\text { Scholarly Activity }\end{array}$ & Service Learning \\
Service Learning \& Civic & Capstone Experiences \\
Engagement & Writing-Intensive Courses \\
Global \& Cultural & Collaborative Assignments \& \\
Competencies & Projects \\
Health \& Wellness & Undergraduate Research \\
& Study Abroad \& Other \\
& Diversity Experiences
\end{tabular}

Figure 1. UCO’s Central Six Tenets juxtaposed against Kuh’s High Impact Practices.

\section{Creating Your Own Synergy}

In the authors' recent presentation at a teaching/learning conference, a participant commented that while he liked the ideas presented, the case history, and the story, his institution remained staunchly siloed and wondered what steps he might take to enhance their synergy. Although the authors responded in the moment, the question has propelled a deeper consideration of the forces 
that make such an effort work. The following are lessons learned and guidance offered, with a cautionary note that this is an on-going process.

\section{People}

Processes such as these always start with people, both in official leadership roles and those at an operational level. Higher-level support is important, though depending upon the level of the action taken; it might mean the dean of a college, a department chairperson, or, as in the case of UCO, vice presidents working with presidential approval.

The active involvement of mid-managers. While formal approval of the transformative learning mission occurred at the VP level, several program directors became involved, offering various experience levels with faculty assignments or different sides of divisional units such as Student Affairs and Administration. Involvement has taken many forms, but one of the most visible is through a structured form of advocacy in which faculty members, recommended by their academic deans, serve as advocates for each of the Central Six Tenets. Deans and unit managers also play a supportive role when they nominate faculty and staff to serve on the university-wide committee that helps with the planning of the annual Transformative Learning Conference (see below) and other activities.

Staff can submit projects for Student Transformative Learning Record (STLR) program (described later), and may serve on projects with faculty and students. One such team, as an example, is involved in a research project related to K-12 and higher education leadership development. Department chairpersons led discussions in departmental meetings to help their faculty determine, for instance, wording on syllabi about the Central Six Tenets. As is always the case, faculty were critically important, and many UCO faculty certainly became "pioneers" in terms of their involvement. The same applies to program directors in areas such as service learning, who eagerly stepped forward and embraced opportunities for collaboration. It is important to respect the contribution of each individual and office, a task partially accomplished by recognizing where each has contributed in their current role. Faculty may say, "I've been doing that (in UCO's case, transformative learning) for a long time," and there is likely truth in that statement. Accepting the current contribution of people is essential.

Personal traits and characteristics. First, some of the people involved in the process must have legitimate authority, with the ability to make things happen. This might be a faculty member directing a class, or a director of the American Democracy Project, or a VP in Academic Affairs. One of the strongest authoritative messages within the UCO plan was the alignment of budgeting processes to elements of transformative learning practice, such as direct support to faculty involving undergraduate students in research efforts. This alignment process had strong support from the UCO Academic Affairs office.

Authentic leaders are second characteristic of people to involve, according to Northouse (2012) in his book Leadership: Theory and Practice. Authentic leaders are individuals who will support efforts to help students learn even when it is beyond their own personal or departmental interests. They will unite their individual interests and the interest of the whole. The UCO Wellness Center's director understood John Ratey's research and his 2008 publication (Spark), which 
showed a significant relationship between health and learning. The director made a great partner in the early transformative learning institutional efforts. He created an interdisciplinary committee to help make connections among faculty, student affairs staff, and Wellness Center personnel. This action-focused team continues to renew itself through a bi-annual needs assessment and planning effort aligned with the mission.

Focus

There is tremendous power in focus, requiring not a rigidity of mind but the ability to adapt while knowing and creating a path. In the early days of the UCO process, an umbrella was identified that allowed the unification of previously disparate programs. That umbrella, as described earlier, was named transformative learning, and the components were the Central Six Tenets. That focus has remained constant through its manifestation in particular programs, morphing and adapting as the environment has changed.

Leaders often feel that it is their charge to create new programs, and UCO did that within the Central Six framework. The Provost and the President both had the commitment to highlight transformative learning and the Central Six in almost every major presentation on and off campus.

This focus and branding of transformative learning and the Central Six coincided for faculty and staff and provided a sharable community terminology. Students have also adopted the terminology, helping to keep the focus. While UCO has not reached unanimity, the central nature of transformative learning is apparent in the ethos: it was the first and primary point in the construction of the most recent strategic plan for 2020.

\section{Alignment}

Alignment has contributed greatly to the progress of UCO transformative learning efforts. Planning, budgeting, policy, and procedure must ensure that decisions are consistent with the focal message, and new programs, academic or co-curricular, need to align in some way. Alignment ought not to restrict innovation, but to encourage it. Transformative learning terminology appears in policies, such as the generic elements of class syllabi, supporting the theme.

Educational and professional development opportunities have encouraged transformative learning. A case of walking the transformative learning talk occurred with the university's 20112012 revitalization of the faculty development unit, raising its profile and re-branding it with the name, “Center for Excellence in Transformative Teaching and Learning." Similarly, the institution financially supports faculty when they make state, regional, and national presentations about the transformative learning model. Internal grant opportunities are available to support course re-design and other activities to find innovative ways to support transformative learning, and on-going development programs have transformative learning as a central theme. 


\section{Learning Space}

The construction of UCO’s Center for Transformative Learning, which opened in 2010, was the ideal symbol for the mission focus, and its thoughtful design continues to function as an ideal learning space. The building, now commonly referred to as the CTL, demonstrated the university's commitment to transformative learning.

The building's design is a dream for faculty if they value interactive learning. The CTL building is spacious, with many areas for students to gather in small groups or one-on-one to study and collaborate, and UCO intentionally designed the classrooms with no "front" so the faculty member is physically encouraged to work with an interactive format. Tables and chairs are all on wheels, allowing faculty to reconfigure the room in a matter of minutes with minimal effort. Classrooms present three walls equipped with displays for the projection of visuals, and two walls are also equipped with rails to support huddle boards (small portable white boards) that can be easily lifted and placed on tables so students can gather around, graphically brainstorm, or create finished visuals, after which boards can be hung up for full-class discussion.

Classrooms in the CTL serve as innovation-prompting instructional spaces for those who teach in them. Each college on campus "owns" two classrooms in the building emphasizing a crossdisciplinary approach to transformative learning. Such an approach realizes a benefit, not solely because more students experience the learning space, but also because of the interdisciplinary collegiality that organically occurs when the faculty member across the hall is from a different college.

The CTL's classrooms have become a model for many other classroom renovations on campus. Amidst a movement in higher education toward friendly, active-engagement learning spaces, UCO's experience with these kinds of instructional environments is favorable from both students and faculty

The institution sent a strong message of support to faculty who wanted to widen their knowledge of instructional strategies, including things like "huddle boards," instantly reconfigurable table/chair layouts, and "frontless" classrooms, by locating the Center for Excellence in Transformative Teaching and Learning (CETTL), the faculty development unit, within the new building. This location puts faculty support inside interdisciplinary teaching space designed specifically to enable and support teaching that transforms students. As faculty development offerings around transformative learning have grown, the CTL has been pressed into service as the space for new faculty training, the meeting area for Learning Communities for the Scholarship of Teaching and Learning, and a gathering place for book discussion groups around transformative learning and other topics. CETTL's 21st Century Pedagogy Institute hosts and supports these meetings and provides an evidence-based structure for faculty to develop and improve teaching practice. 


\section{Courageous Collaboration}

Collaboration is not easy in any setting and usually involves shifts in power dynamics. If perceived as a zero-sum game, someone must lose while someone else wins; however, with a strong focus and committed individuals, collaboration can become synergistic, a true win-win opportunity. Collaboration is not just a matter of finding the right people: leaders must frequently reiterate their support for the collaborative ventures, especially in high-profile meetings and public forums. If there is a give-and-take involved in the process, then top-level leadership must be sure to provide that support. Nothing should be lost because of collaboration, with position and authority undiminished as a consequence of collaborative effort.

The same holds true for innovative processes; faculty may feel vulnerable to innovations that have a risk of failure, as it could negatively affect student evaluations and potentially put promotion or tenure at risk. Such circumstances are a good example of how and where the faculty development operations can be pro-active with information, workshops, consultations, and other supportive activities. In addition, administration has the opportunity to be congruent in its message and execution that experimentation, in order to create more transformation-prone learning activities and environments, will be honored, as in the UCO model. This creates the sense that faculty and administration are all working toward the same goals by actions, not just words.

One initiative at UCO, designed specifically with alignment in mind, was the Transformative Learning Steering Committee, a group that began initially as a conference committee managing a campus-wide day of discussions about transformative learning. From its inception, the committee was comprised of representatives from Academic Affairs (including faculty), Administration, Information Technology, and Student Affairs.

In late 2012, the Provost and the Vice President of Student Affairs charged the committee with a new mission: to be the "face of" transformative learning at UCO, transforming it into a steering committee with a much broader purpose and responsibility. Concurrent with this change the Transformative Learning Conference (http://www.uco.edu/tlconference) took on a new, higher level of prominence, moving from a solely UCO event and conversation to being an off-campus, metropolitan-venue conference with high-profile keynotes and featured presenters, while still

maintaining a conversation-based approach in concurrent sessions about transformative learning. This raised profile of the conference has helped it grow; it is now in its 12th year. 


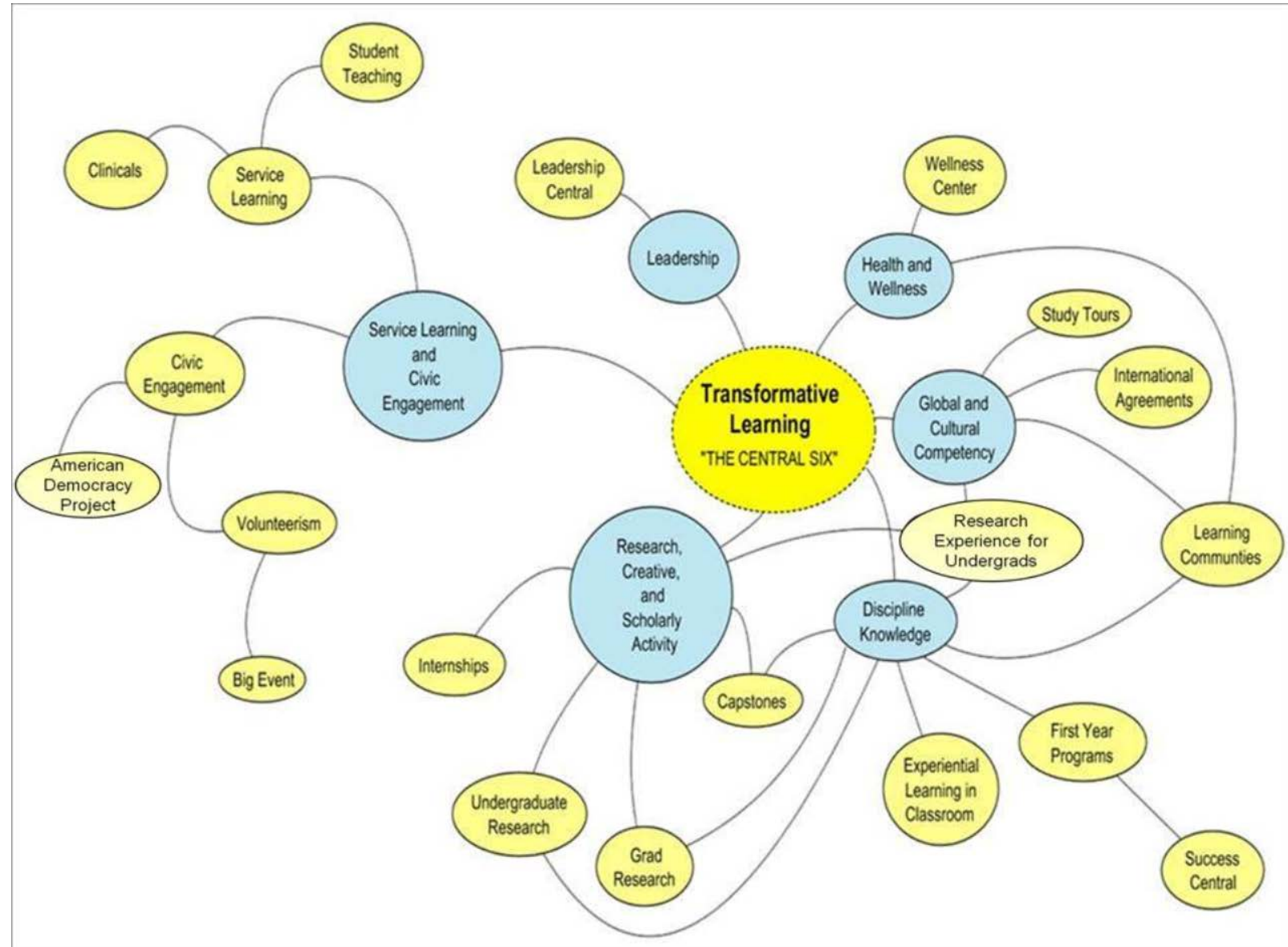

Figure 2. Individual components of UCO’s Transformative Learning Initiative.

\section{Assessment}

As mentioned previously, the small group that was first to use the terminology "transformative learning," had initially come together to talk about issues of assessment. It was important, therefore, to identify or create tools and processes to measure the degree of success in helping students develop within the areas that were to become the Central Six Tenets. UCO still struggles, on occasion, with specific aspects of the assessment process, but has found various answers in different locations that may assist others.

Transformative learning is not so different as an approach to teaching and learning that it varies dramatically from widely regarded good practices in assessment. For example, Angelo and Cross (1993) identify seven basic assumptions about good assessment (pp. 7-11), and Astin, along with his eleven co-authors, present nine principles of good practice for assessing student learning (1992). Guidelines for quality assessment such as these apply to transformative learning, as does the rationale for authentic assessment (Wiggins, 1990).

Assessment of transformative learning must address both the individualized nature of the process and the meta-conceptual framework; measuring it at the micro-level might satisfy some but could easily miss the larger focus. Transformative learning serves as a guiding principle, often 
reflected in some meta-type instruments, such as NSSE (National Survey of Student Engagement) and UCO’s GSS (Graduating Student Survey). Similar large-scale instruments can also help present a broader picture-the American College Health Association-National College Health Assessment, for example. This certainly tells us something about our success with students relative to our Health and Wellness Tenet among the Central Six There is also useful information within a variety of discipline-related instruments often used for special accreditation, and it is only a matter of mining the data to use this information. Requirements from disciplinary accreditors to assess the degree to which students achieve learning outcomes, for example, can provide opportunities to measure success in areas such as those represented by our Central Six.

Because UCO is one of the institutions participating in The Quality Assurance Commons Essential Employability Qualifications Certification (EEQ Cert: https://theqacommons.org) project, a Lumina Foundation-funded initiative, the institution is working with other institutions to help define what a certification process might look like concerning beyond-disciplinary skill development within programs and across UCO. Student development in our Central Six maps directly to EEQs as conceived by The Quality Assurance Commons, ultimately providing yet another mechanism to assess transformative learning efforts.

As UCO continues to refine its assessment of transformative learning, its Institutional Assessment unit is adapting as useful measuring tools the Association of American Colleges and Universities (AAC\&U) VALUE Rubrics (Valid Assessment of Learning in Undergraduate Education) which connect to the institution's Central Six Tenets. These rubrics, for instance, are figuring prominently in UCO's continuing refinement of the Core Curriculum.

Each individual has a unique story of transformation, and those stories can be gathered and analyzed via qualitative analysis techniques. UCO’s Transformative Learning Steering Committee has been engaged in this research approach, directing IRB-approved research projects employing both qualitative and quantitative analysis of information gathered in surveys, one-onone interviews, focus groups, student narratives about transformative learning, and from other sources. In addition, the Assistant Director dedicated to assessment of UCO's Student Transformative Learning Record initiative (see below) leads a robust evaluation of how well faculty members are implementing transformative learning practice and to what degree students are benefitting from it.

Anecdotes and qualitative analysis are extremely useful and powerful sources of information, especially related to concepts with inextricable affective components like those inevitable in transformative experiences (Taylor, 2001). At the same time, there are many aspects of transformative learning that result in student change in psychomotor and cognitive domains, and it is important to capture those gains as well.

UCO has now added student transformative learning achievement data (as generated via the STLR process described below) into institutional data analytics and the predictive modeling mix. In advance of that, fall 2015 to fall 2016 student achievement and retention results showed the transformative learning tool and process associating with strong positive gains, in many cases into the double digits (and verified at $p<.001$ levels for these large- $N$ analyses). Subsequent fall2016-entering students tracked into their sophomore years as well as fall 2015 students tracked 
into their junior years also show double-digit retention numbers compared to students who did not have the transformative learning experiences generated via STLR. These gains are shrinking the gaps in achievement and retention that have existed between students who are and who are not low socio-economic-status (SES), underrepresented, and/or first-generation. The data for the entering cohort of first-time/full-time freshman in fall 2016 show improved gains, indicating that STLR creates an improving positive impact.

Regarding assessment, the suggestion would be for institutions to use what they have while pursuing what they think might be a better tool to assess success with something as ambitious as transformative learning.

\section{Transformative Learning: A “Stellar” Approach}

Though transformative learning as an organizing principle may have arisen organically at UCO, the university community has become intentional in designing assignments, activities, and environments meant to prompt student transformative experiences. The institution conceived the Student Transformative Learning Record (STLR, pronounced "stellar": http://www.uco.edu/stlr) process as a crucible of intentionality for transformative learning, and committed institutional funding to move ahead. Six months later, the vision for STLR gained validation, in the form of a multi-year U.S. Department of Education Title III Strengthening Institution Program Grant of several million dollars.

Briefly, STLR is a process whereby faculty connect at least one assignment in their courses to one or more of UCO's Central Six Tenets. The assignment is usually an existing one that, with careful planning, can connect to a tenet and produce a student-learning artifact that faculty may assess using STLR rubrics (built on the AAC\&U VALUE rubrics, mentioned above). Faculty eventually push the artifact, the rubric used to assess it, and the achievement level reached to the student's STLR e-portfolio.

An example: For years, a statistics instructor has used a dataset from a textbook for an assignment on Central Limit Theorem. By using, instead, a real-world database describing kilometers walked from different villages to the nearest sources of potable water, the instructor could add a reflective prompt to the assignment associated with UCO's Global and Cultural Competencies (GCC) Tenet. Such a prompt might intend to elicit students' perspectives about the differences between their lives and the lives represented in the statistics students accessed for the assignment. The instructor will grade the assignment as usual but then assess the STLR artifact (the written reflection) using the GCC rubrics.

A similar process exists for co-curricular learning, except that students attending a Student Affairs event, where "student-teacher ratios" might be hundreds to one, automatically attain only the lowest level of transformative engagement, "Exposure," by virtue of a student ID card-swipe process integrated into STLR. Student Affairs professionals manage by exception those students who might deserve a higher rating, requiring an artifact of those students and assessing it using the STLR rubrics. UCO devised an awkward but effective way to capture this in a Learning Management System "pseudoshell” created for the event. For example, the Asian Moon Festival 
becomes a "course shell” where Student Affairs staff can assess the transformative learning artifact requested of a student who demonstrated leadership in organizing the event.

A mobile student app allows students to track their progress across all three levels of potential transformative impact — "Exposure," "Integration," and "Transformation"—in each of the Tenets. In a future phase of the app, students will be able to see upcoming term tenet-associated courses (down to the section level) and Student Affairs activities as they plan their course schedules.

The STLR e-portfolio might be the “end product” of UCO’s transformative learning concerning what students do with the proof of their achievement within each of its tenets. Graduates can grant to a potential employer access to the two best exemplars in their e-portfolios of a tenet particularly relevant for the sought-after job, for instance, in advance of job interviews. UCO has been working closely with its STLR Employer Advisory Board, but knew previously that employers wanted to know more about potential hires than what shows on their academic transcripts.

UCO believes the STLR e-portfolio will provide such information to potential employers. The eportfolios, though, are not mere repositories of STLR artifacts. Students must create useful, employer-friendly presentations of self that provide quick answers to what hiring managers want to know. This means institutions must train students in the creation of their STLR e-portfolios, potentially within capstone courses, which are required in all UCO programs.

While the STLR e-portfolio is where students present tangible proof of transformative learning, a student-customized presentation of STLR achievement conveniently appears on the UCO Comprehensive Student Record (CSR), which unifies a record of STLR achievement with the academic transcript. Students have control of the STLR portion of their CSRs and are able to customize multiple versions, similar to what one might do in customizing versions of a résumé. UCO believes this is important, as students make sense of their beyond-disciplinary learning and make choices to prioritize experiences as they present themselves to others. They can only customize, however, from among their official STLR achievements, thereby ensuring the integrity of the information via an evidence-based, authentic assessment process. As a unification of the academic transcript and the STLR record, the CSR is official in every way and carries the registrar's stamp.

With the CSR now in operation and students able to access and customize these records, UCO is in early stages of requiring CSRs when students apply for positions on campus, student worker opportunities, on-campus internships, and as part of application packages for awards. The purpose is for CSRs to provide formative developmental opportunities. Students create the CSR version they believe best supports their application, then discuss how and why the CSR demonstrates their development of the skills and ethos required to perform the duties for which they are being considered or to support their worthiness to receive the recognition for which they have been nominated. UCO students thereby gain experience in applying and interviewing for opportunities during the course of their time at the institution; such experience can prove valuable when seeking employment and/or graduate school admission. 
The STLR tool and process also struck a chord with grant funders. The first was the large Title III grant from the U.S. Department of Education (mentioned above) which allowed UCO to expand faster than the original timeline devised to operationalize transformative learning when funded with only institutional funds. Next, UCO gained an invitation to the 2015 cohort of the Next Generation Leadership Challenge Breakthrough Models Incubator cohort, led by Educause and supported by the Gates Foundation.

More recently, UCO joined the initiative led by NASPA (National Association of Student Personnel Administrators) and AACRAO (American Association of Collegiate Registrars and Admissions Officers) and funded by the Lumina Foundation to be among the 12 institutions selected to design a "Comprehensive Student Record" (above). The project highlighted institutions doing innovative work to document beyond-disciplinary learning. It provided the impetus for UCO to design its CSR. Additionally, UCO received a 2016 Western Interstate Commission for Higher Education Cooperative for Educational Technologies (WCET) Outstanding Work Award for STLR.

Most recently, the institution's work with STLR has garnered an invitation to the Lumina Foundation-supported Quality Assurance Commons' Essential Employability Qualities (EEQ) project (also introduced above). Lumina-EEQ further invited UCO's Forensic Science program, as the program-level participation in place for the 14 institutions invited to the project. Because of STLR, UCO also garnered an invitation at the institution level given STLR's reach across all programs. Finally, and perhaps the most validating statement about UCO's approach, is the fact that multiple other institutions are now in process adopting/adapting STLR on their own campuses. UCO has been gratified that these adoptees include both U.S. and international institutions. Adoption by other institutions has gained further momentum, given the charge in the Title III grant that what the institution produces must be platform-agnostic, replicable, and scalable. It's also the case that STLR has passed muster with regional accreditors, both at UCO (Higher Learning Commission) and at a STLR-adopting/adapting institution, Western Carolina University (Southern Association of Colleges and Schools), which made its version of STLR the focus of its Quality Enhancement Plan for its institutional reaccreditation.

\section{Conclusion}

The UCO journey has been rewarding, frustrating, challenging, frightening, and always interesting. It has been a movement from practice to theory in terms of the recognition of the transformative learning framework, and that has worked well. This journey has also benefitted from serendipitous circumstances within the framework of strategic planning. The institution learned as it found its way, repeating a favorite expression, "building the plane while we're flying it," during the course of the journey. However, a general knowledge of systems, processes, project management, and teaching/learning theory have helped inform UCO at many places along the way. Most importantly, this journey toward transformative learning as an operational approach for teaching and learning has been about professionals committed to the broader purpose of the institution, the mission, and to creating ways to help students learn. 


\section{References}

Angelo, T. A., \& Cross, K. P. (1993). Classroom assessment techniques: A handbook for college teachers (2nd ed.). San Francisco, CA: Jossey-Bass.

Astin, A. W., Banta, T. W., Cross, K. P., El-Khawas, E., Ewell, P. T., Hutchings, P., Marchese, T. J., McClenney, K. M., Mentkowski, M., Miller, M. A., Moran, E. T., \& Wright, B. D. (1992). Nine principles of good practice for assessing student learning. Washington, D.C.: American Association of Higher Education (now known as the American Association for Higher Education and Accreditation). Retrieved March 19, 2017, from http://teaching.uncc.edu/sites/teaching.uncc.edu/files/media/files/file/AssessmentAndGrading/9P rinciples.pdf

Benjamin, A. \& Crymble, B. (2017). A re-imagination of the transition to adulthood. In A. Laros et al. (Eds.), Transformative learning meets Bildung (pp. 247-258). San Francisco: Jossey-Bass. https://doi.org/10.1007/978-94-6300-797-9_20

Cranton, P. (2002). Teaching for transformation. New Directions for Adult and Continuing Education, 2002 (93), 63-72. https://doi.org/10.1002/ace.50

Dirkx, J. (2012). Nurturing soul work. In E. Taylor, P. Cranton, \& Associates (Eds.). The handbook of transformative learning, theory, research and practice. San Francisco: Jossey-Bass.

Kuh, G. D. (2008) High-Impact educational practices: What they are, who has access to them, and why they matter. Washington DC: AAC\&U Publications.

Illeris, K. (2014). Transformative learning and identity. London: Routledge.

Mezirow, J. (1981). A critical theory of adult learning and education. Adult Education, 32 (1), 324. https://doi.org/10.1177/074171368103200101

Mezirow, J. (1990). How critical reflection triggers transformative learning. In J. Mezirow \& Associates (Eds.), Fostering critical reflection in adulthood: A guide to transformative and emancipatory learning (pp. 1-20). San Francisco: Jossey-Bass.

Mezirow, J. (1997, Summer). Transformative learning: Theory to practice. New directions for adult and continuing education, 1997(74), 5-12. https://doi.org/10.1002/ace.7401

Mezirow, J. (2000). Learning as transformation: Critical perspectives on a theory in progress. San Francisco, CA: Jossey-Bass.

Morrell, A. \& O’Connor, M. A. (2002). Introduction. In E. O’Sullivan, A. Morrell, \& M.A. O’Connor (Eds.). Expanding the boundaries of transformative learning: Essays on theory and praxis (pp. xv-xx). New York: Palgrave. https://doi.org/10.1525/california/9780520228627.003.0001 
Nicol, D. J., \& Macfarlane-Dick, D. (2006). Formative assessment and self-regulated learning: A model and seven principles of good feedback practice. Studies in Higher Education 31 (2), 199218. https://doi.org/10.1080/03075070600572090

Northouse, P. (2012). Leadership: theory and practice. Los Angeles: Sage.

Ratey, J. (2008). Spark. New York: Little, Brown.

Taras, M. (2005). Assessment—summative and formative-theoretical reflections. British Journal of Educational Studies, 55 (4), 466-478. https://doi.org/10.1111/j.14678527.2005.00307.x

Taylor, E. W. (2001). Transformative learning theory: A neurobiological perspective of the role of emotions and unconscious ways of knowing. International Journal of Lifelong Education, 20 (3), 218-236. https://doi.org/10.1080/02601370110036064

Taylor, E., Cranton, P., \& Associates (Eds.). (2012). The handbook of transformative learning, theory, research and practice. San Francisco: Jossey-Bass.

Transformative Learning Home. (2018, April 16). University of Central Oklahoma. Retrieved from http://sites.uco.edu/central/tl/index.asp

University of Central Oklahoma. (2018). University mission, vision statement, strategy statement, and call to action. Retrieved April 4, 2015, from http://www.uco.edu/about/mission.asp

Wiggins, G. (1990). The case for authentic assessment. ERIC document retrieved March 19, 2017, from http://files.eric.ed.gov/fulltext/ED328611.pdf 


\section{Author Information}

Ed Cunliff is professor of Adult and Higher Education at the University of Central Oklahoma with a consulting practice in transformative learning and authentic leadership. Ed's seeks to help learners achieve their goals, which he accomplishes through teaching/facilitating learning in the Adult and Higher Education program at the University of Central Oklahoma. Teaching and research interests include adult learners, applied research, transformative learning, managing adult education programs, and the organization and administration of higher education.

*Ed Cunliff

Department of Adult Education and Safety Sciences

University of Central Oklahoma

100 N. University Drive

Box 206, CTL 221

Edmond, OK 73034

Email: ecunliff@uco.edu

Telephone: 405-974-2972

Jeff King is Executive Director of the Center for Excellence in Transformative Teaching and Learning at the University of Central Oklahoma. He also leads the Student Transformative Learning Record (STLR) initiative, which is comprised of the processes, tools, and infrastructure UCO employs to operationalize Transformative Learning. As part of his STLR duties, Jeff works with other institutions who have adopted or adapted STLR to their own campuses, missions, and cultures.

Jeff King

Center for Excellence in Transformative Teaching and Learning University of Central Oklahoma

100 N. University Drive

Box 212, CTL 205

Edmond, OK 73034

Email: jking47@uco.edu

Telephone: 405-974-5544

*Corresponding author 